\title{
Kehidupan sosial remaja pengguna narkotika, psikotropika dan zat adiktif di Surabaya
}

\section{The social life of youth users of narcotics, psychotropics, and addictive substances in Surabaya}

\author{
Fuad Bachtiar ${ }^{凶}$ \\ Departemen Sosiologi Fakultas Ilmu Sosial dan Ilmu Politik, Universitas Airlangga \\ Surabaya, 60286, Jawa Timur, Indonesia \\ E-mail corresponding author: fuad.bachtiar-2014@fisip.unair.ac.id
}

\begin{abstract}
Abstrak
Penyalahgunaan narkotika, psikotropika dan zat adiktif (NAPZA) di kalangan remaja merupakan salah satu bentuk kenakalan yang dilakukan oleh remaja. Terdapat fakta bahwa beberapa remaja pengguna NAPZA di Kota Surabaya tidak terlihat seperti pecandu NAPZA, mereka memiliki kontrol emosi untuk mengelabuhi orang di sekitarnya, kemudian saat berada pada kelompok pengguna ia akan berperilaku bebas. Perilaku seperti ini dapat dikatakan merupakan sebuah dramaturgi belaka. Penelitian ini menggunakan pendekatan kualitatif. Penelitian berada di Kota Surabaya. Informan sebagai subjek penelitian dipilih dengan cara snowball dan diperoleh sebanyak lima informan. Teori atau perspektif teoritis yang digunakan dalam studi ini adalah kerangka teori dramaturgi oleh Erving Goffman. Hasil penelitian menunjukkan kehidupan sosial remaja pengguna NAPZA memiliki perbedaan sikap dan perilaku pada saat berada di lingkungan sekolah dan di lingkungan rumah untuk menutupi identitas bahwa dirinya merupakan seorang pengguna. Manajemen kesan pun dilakukan dengan sebaik mungkin seperti tidak akan membocorkan identitas diri pada orang yang baru dikenal. Berdasarkan hasil temuan data cenderung mampu membedakan sikap dan perilaku, bahwa remaja pengguna NAPZA dalam berperilaku dalam lingkungan kelompok pengguna dan di luar kelompok pengguna NAPZA.
\end{abstract}

Kata Kunci: remaja; NAPZA; kehidupan sosial; perbedaan perilaku; identitas ganda

\begin{abstract}
It is a known fact that youth users of narcotics, psychotropics, and addictive substances (NAPZA) in Surabaya are unlike others: they have emotional control to trick people around him into thinking that they are not drug users. They only show their drug problems among their peers of users. It is a mere stage act. This research was done in the area of Manukan, Tandes, and other western parts of Surabaya using a qualitative approach. Five informant were selected using snowball sampling. Collecetd data were then analyzed using the framework of dramaturgy theory by Erving Goffman. Results of the study show that the social life of NAPZA users are differentiated according to the surroundings. Users perform particular attitude and behavior to cover their identity as users in schools and homes-different to those they show within group of other users. In addition, they carefully execute impression management so as to not disclose their identity to new people.
\end{abstract}

Keywords: youth; drugs; social life; behavioral differences; double identity

\section{Pendahuluan}

Penggunaan NAPZA di Jawa Timur dalam kurun waktu tiga tahun terakhir mengalami fluktuasi yang signifikan (Nur'artavia 2017; Prasetyo \& Prawiradiredja 2019). Hal itu dapat dibuktikan dari laporan hasil media online merdeka.com bahwa pada tahun 2017 total pengguna narkoba di kalangan pelajar Surabaya meningkat. Sejak tahun 2016 ke tahun 2017 terjadi peningkatan signifikan sebesar 118 pelajar positif mengkonsumsi narkoba. Data tersebut disampaikan oleh AKBP Suparti kepala BNN Kota Surabaya. Dalam pernyataan tersebut AKBP Suparti menjelaskan bahwa besaran angka penyalahgunaan narkoba pada remaja di Jawa Timur terutama di Kota Surabaya cenderung meningkat dibandingkan tingkat kabupaten. Alasan remaja menggunakan NAPZA adalah rasa ingin tahu atau coba-coba dan bersenang-senang. Dari data BNN kecenderungan penyerangan narkoba di tahun 2015 cukup tinggi, kemudian tahun 2016 turun, dan di tahun kembali 2017 naik.

NAPZA merupakan singkatan dari narkotika, psikotropika, dan zat adiktif. Jenis narkotika di antaranya adalah heroin, opium, ganja, morfin, dan kokain. Jenis psikotropika di antaranya ekstasi, 
sabu, amfetamin, dan pil koplo. Sedangkan zat adiktif lainnya adalah alkohol, inhalas (lem, tinner, bensin, penghapus cat kuku), tembakau, dan kafein (UU 35 Tahun 2009 tentang Narkoba). Sementara itu, narkotika ada tiga golongan. Golongan pertama adalah untuk pengembangan ilmu misal: heroin, kokain, ganja, golongan kedua adalah untuk pengobatan misal: morfin dan ketiga adalah gabungan keduanya (Purwatiningsih 2001). Namun seiring perkembangan Narkotika ini adalah jenis NAPZA yang paling marak disalahgunakan khususnya pada kalangan remaja (Simanungkalit 2012; Suyatna 2018).

Sementara itu, remaja adalah mereka yang mengalami fase-fase perkembangan selama masa hidupnya. Papilia, Old, Feldman (2009:206) mengungkapkan bahwa remaja adalah transisi perkembangan antara masa kanak- kanak dan masa dewasa yang mengalami perubahan besar pada fisik, kognitif dan psikososial. Individu dikatakan remaja apabila individu tersebut telah berumur antara 12 tahun hingga 22 tahun (Agustiani, 2006:29). Batasan usia remaja menurut WHO (2007) adalah 12-24 tahun. Masa pertumbuhan remaja seringkali diwarnai dengan munculnya karakteristik yang disebut "krisis identitas" (Oleś 2016; Kroger 2017). Masa individu harus memutuskan siapa dia, apa yang dia lakukan, dan apa yang dilakukan dalam hidupnya. Akibatnya remaja sangat peka terhadap stress, frustasi, dan konflik. Hal itu dapat dimungkinkan terjadi karena pada proses tersebut remaja mengalami pergolakan dalam jiwanya untuk mencari jati diri (Star 2010).

Perkembangan yang dilalui remaja mencakup hal kognitif maupun psikososial yang dapat mempengaruhi kehidupan remaja dalam bertindak dan berperilaku (Baumister \& Muraven 1996; Marcia 2010). Dinamika psikososial pada kehidupan remaja dapat mempengaruhi perilaku dan pergaulannya. Adapun pergaulan dikalangan remaja pada umumnya mempunyai dampak yang positif ataupun negatif bagi remaja tersebut. Apabila remaja dapat memilih teman yang memberikan dampak positif dalam berperilaku maka remaja akan berperilaku sesuai dengan norma sosial yang ada (Crocetti 2017). Namun sebaliknya apabila pergaulan yang dipilih remaja tersebut memiliki dampak negatif maka akan memberikan dampak buruk pula dalam kehidupan sosial remaja.

Perubahan penyesuaian diri pada remaja tergantung dari kecepatan remaja melakukan penyesuaian diri pada lingkungan sosial yang dipilih oleh remaja untuk menghabiskan waktu luang yang dimilikinya (McBrien et al. 2017; Young 2018). Perubahan dari perilaku sosial remaja tersebut bisa membuat remaja menjadi individu yang lebih kreatif dan memiliki dampak yang baik bagi diri remaja ataupun teman remaja, begitu pula sebaliknya dapat membuat remaja melakukan perubahan lingkungan sosial seperti melakukan perilaku yang tidak sesuai dengan norma sosial yang ada atau merugikan dirinya dan lingkungannya (Septanto 2019). Remaja lebih banyak berada di luar rumah dengan teman- teman sebaya sehingga pengaruh teman-teman sebaya pada sikap, pembicaraan, minat, penampilan, maupun perilaku lebih besar daripada pengaruh keluarga (Spencer et al. 2001; Burrow \& Hill 2011). Perilaku remaja yang lebih memilih untuk menghabiskan waktu bersama dengan teman sebaya adalah salah satu proses yang dilalui remaja dalam memilih dan memilah teman pergaulan. Remaja akan merasa nyaman bersama dengan teman apabila mempunyai minat dan perilaku yang sama (Hurlock 1996:213).

Tidak hanya dengan lingkup sosial yang mengalami perubahan, namun juga sebenarnya minat pada remaja juga berubah (Phinney et al. 1990). Dalam masa remaja, minat yang dibawa dari masa kanakkanak berkurang dan diganti oleh minat yang lebih matang. Hal ini dikarenakan pada tahap remaja, tanggung jawab pribadi akan lebih besar dibandingkan pada saat masa kanak-kanak. Sebagai tambahan, Hurlock (1996:217) menemukan bahwa pengalaman juga membantu remaja untuk menilai minatnya secara lebih kritis dan untuk mengetahui mana hal yang benar- benar lebih penting bagi dirinya.

Terdapat fakta bahwa beberapa remaja usia sekolah SMP dan SMA di Kota Surabaya menggunakan NAPZA jenis pil dan miras yang paling banyak ditemui (Pina \& Soedirham 2015; Madyaratri 2017; Sari 2018). Berdasarkan data BPS tahun 2017, bahwa kenakalan yang dilakukan remaja kategori konsumsi NAPZA terutama narkoba khususnya di kecamatan Tandes adalah terbesar, sebagaimana data BPS tahun 2017 sebagai berikut jenis tindak pidana atau kriminalitas paling menonjol yang 
dilakukan oleh para remaja adalah tindak pidana pencurian. Perbuatan tindak pidana pencurian dilakukan oleh sebanyak 120 remaja atau sekitar 60 persen dari keseluruhan remaja nakal. Kemudian bahwa jenis tindak pidana menonjol lainnya berturut-turut adalah tindak pidana narkoba $(9,5$ persen), perkosaan/pencabulan (6 persen), kecelakaan lalu lintas yang mengakibatkan kematian orang lain (5 persen), pengeroyokan (4 persen) dan penganiayaan (4 persen).

Hal ini berarti bahwa tindak kriminal konsumsi narkoba/NAPZA berat pada kategori tertinggi kedua setelah pencurian (Unayah \& Sabarisman 2016). Dan dari 9,5\% tersebut, 3\% penyumbang terbesar pengonsumsi napza merupakan dari kecamatan Tandes. Akan tetapi, remaja ini memiliki kontrol emosi dan kepribadian yang cukup bagus dan mengelabuhi orang (Santoso \& Silalahi 2000). Saat di sekolah beberapa remaja tersebut bersikap baik, berteman dengan siapapun dan menutupi bahwa dirinya merupakan seorang pengguna NAPZA, kemudian saat berada pada pergaulan kelompoknya di luar sekolah yakni kelompok pengguna ia akan berperilaku bebas, berkata sebanyak mungkin bahkan hal-hal yang tidak jelas pun dibahasnya.

Perilaku seperti ini dapat dikatakan merupakan sebuah dramaturgi belaka. Dapat disebut bahwa lingkungan sekolah merupakan front stage pengguna dimana ia akan memberikan kesan yang baik, mengendalikan audiens (guru, teman sekolah) sebaik mungkin, dalam sekolah ia akan menciptakan manajemen kesan yang baik. Sedangkan lingkungan pergaulan pengguna merupakan back stage dimana pengguna akan sangat jauh berbeda perilaku, interaksi nya dibandingkan dengan front stage. Berdasarkan paparan data tersebut, maka studi ini berusaha mengkaji bagaimana kehidupan sosial remaja penggunaan NAPZA dalam kehidupan lingkungan serta bagaimana perilaku remaja pengguna NAPZA di lingkungan kelompok pengguna dan di luar lingkungan kelompok pengguna.

Dramaturgi adalah teori seni teater yang dicetuskan oleh Aristoteles dalam karya agungnya Poetic (350 SM) yang di dalamnya terdapat kisah paling tragis Oedipus rex dan menjadi acuan bagi dunia teater, drama, dan perfilman sampai saat ini (Halliwell 1998; Kirby 2018). Kemudian dikembangkan oleh Erving Goffman Margaret, seorang sosiolog interaksionis dan penulis melalui pendekatan sosiologis. Dia menyempurnakan lebih praktis dalam bentuk interaksi simbolik tentang kehidupan sosial sehari-hari yang kemudian termanifestasi dalam bukunya The Presentation of Self in Everyday Life dan menjadi terkenal sebagai salah satu sumbangan terbesar bagi teori ilmu sosial.

Pada perkembangannya, dramaturgis begitu banyak dikenal dan dijadikan sebagai bentuk komunikasi lainnya dalam kehidupan sehari-hari manusia. Teori dramaturgis mejelaskan bahwa identitas manusia adalah tidak stabil dan setiap identitas tersebut merupakan bagian kejiwaan psikolog yang mandiri. Identitas manusia bisa berubah-ubah tergantung dari interaksi dengan orang lain. Dalam dramaturgi, interaksi sosial dimaknai sama dengan pertunjukan teater. Manusia adalah aktor yang berusaha untuk menggabungkan karakteristik personal dan tujuan kepada orang lain melalui pertunjukan dramanya sendiri. Dalam mencapai tujuan tersebut, menurut konsep dramaturgi manusia akan mengembangkan perilaku-perilaku yang mendukung perannya tersebut.

Di dalam sosiologi naturalis, individu dilihat sebagai aktor yang melakukan tindakan semata sebagai tanggapan langsung terhadap rangsangan sosial yang melembaga. Sesuai dengan gambaran manusia yang determinis. Maka isu tentang penafsiran atau pemaknaan yang diberikan interaksi sosial dilewatkan begitu saja sesuai model naturalistik. Teori Goffman sebagaimana teori Homans, menanggapi individu (bukan struktur yang lebih besar) sebagai suatu analisa. Akan tetapi beda dengan Homans, Goffman tidak menggunakan teori ilmiah lainnya, karena Goffman menggunakan analogi drama dan teater. Pembahasan lebih lanjut ini ia tulis dalam bukunya yang berjudul The Presentation of Self in Everyday Life, pada tahun 1959 yang membahas secara mendalam tentang bagaimana individu tampil di dunia sosial. Sebagaimana dalam penelitian ini akan membahas dua peran remaja sebagai penyalahgunaan NAPZA dan sebagai remaja dalam masyarakat sosialnya.

Selayaknya pertunjukan drama, sang aktor drama kehidupan juga harus mempersiapkan kelengkapan pertunjukan. Kelengkapan yang dimaksud ini antara lain memperhitungkan setting, kostum, penggunaan kata (dialog) dan tindakan non verbal lain, hal ini tentunya bertujuan untuk meninggalkan 
kesan yang baik pada lawan interaksi dan memuluskan jalan mencapai tujuan. Erving Goffman mengistilahkan tindakan di atas dalam istilah Impression Management. Goffman juga melihat bahwa ada perbedaan acting yang besar saat aktor berada diatas panggung (front stage) dan dibelakang panggung (back stage) drama kehidupan. Kondisi acting di front stage adalah adanya penonton yang melihat kita dan kita sedang berada dalam kegiatan pertunjukan. Saat itu kita berusaha untuk memainkan peran kita sebaik- baiknya agar penonton memahami tujuan dari perilaku kita.

Perilaku kita dibatasi oleh konsep-konsep drama bertujuan untuk membuat drama yang berhasil. Sedangkan back stage adalah keadaan dimana kita berada dibelakang panggung dengan kondisi bahwa tidak ada penonton. Sehingga kita dapat berperilaku bebas tanpa memperdulikan plot perilaku bagaimana yang harus kita bawakan. Erving Goffman mendalami dramaturgi dari segi sosiologis. Beliau menggali segala macam perilaku interaksi yang kita lakukan dalam pertunjukan kehidupan kita sehari-hari yang menampilkan diri kita sendiri dalam cara yang sama dengan cara actor menampilkan karakter orang lain dalam sebuah pertunjukan drama.

Cara yang sama ini mengacu kepada kesamaan yang berarti ada pertunjukan yang ditampilkan. Goffman mengacu pada pertunjukan sosiologi, pertunjukan yang terjadi di masyarakat untuk memberi kesan yang baik untuk mencapai tujuan, ini adalah penerimaan penonton akan manipulasi. Bila seorang aktor berhasil, maka penonton akan melihat aktor sesuai sudut yang memang ingin diperlihatkan oleh aktor tersebut. Aktor akan semakin mudah untuk membawa penonton untuk mencapai tujuan dari pertunjukan tersebut. Ini dapat dikatakan sebagai bentuk lain dari komunikasi, karena komunikasi sebenarnya adalah alat untuk mencapai tujuan.

\section{Metode Penelitian}

Berdasarkan masalah yang diteliti, penelitian ini menggunakan metode kualitatif. Bogdan dan Taylor (dalam Moleong 2000) mendefinisikan metode kualitatif sebagai prosedur penelitian yang menghasilkan deskripsi berupa kata- kata tertulis atau lisan dari orang- orang dan perilaku yang dapat diamati. Penelitian ini mengambil lokasi di kota Surabaya bagian Barat, yaitu di wilayah Manukan, Tandes.

Dalam penelitian ini, teknik penentuan informan menggunakan teknik snowball. Untuk menghindari terjadinya kesalahan dalam memilih informan, peneliti menetapkan beberapa kriteria antara lain: (1) Remaja pengguna NAPZA (2) Informan berada pada tahap usia remaja akhir penurut tahap perkembangan remaja oleh Erikson serta WHO dengan mnetapkan batasan usia 17-21 tahun, pada usia tersebut gejolak jiwa remaja sudah cukup stabil untuk selanjutnya akan beralih pada tahap perkembagan individu dewasa. Dengan menggunakan teknik snowball, diharapkan peneliti dapat memperoleh informasi yang banyakberdasarkan petunjuk dari informan pertama serta membangun kepercayaan kepada informan selanjutnya dari informan kunci yang pertama kali peneliti jumpai. Setelah informasi dari informan pertama sudah dirasa cukup maka peneliti bertemu dengan informan selanjutnya yang sesuai dengan kriteria yang diteliti terkait dengan fokus permasalahan pada penelitian ini, hingga informasi yang peneliti ingin ketahui terpenuhi.

Teknik pengumpulan data yang dilakukan diantaranya adalah mengumpulkan data melalui wawancara langsung secara mendalam (indepth interview) dengan menggunakan pedoman wawancara (interview guide) dan observasi. Teknik pengumpulan data didasarkan pada percakapan intensif dengan suatu tujuan untuk menjawab fokus penelitian berdasarkan jawaban yang diperoleh dari informan penelitian.

Kegiatan analisis data terdiri dari tiga alur kegiatan yang terjadi bersamaan, yaitu reduksi data, penyajiandata, penarikan kesimpulan. Reduksi data dapat diartikan sebagai proses pemilihan, pemusatan perhatian pada penyederhanaan, pengabstraksian, dan transformasi data kasar yang muncul dari catatan-catatan tertulis dilapangan. Setelah melalui proses reduksi dan penyajian data, kemudian peneliti melakukan verifikasi dan menarik kesimpulan dengan mencari makna dari setiap gejala yang diperoleh di lapangan. 


\section{Hasil dan Pembahasan}

Sebelum berinteraksi dengan orang lain, seseorang pasti akan mempersiapkan perannya terlebih dahulu, atau kesan yang ingin ditangkap oleh orang lain (Tseëlon 1992; Smith 2006). Kondisi ini sama dengan apa yang dunia teater katakan sebagai "breaking character". Dengan konsep dramaturgis dan permainan peran yang dilakukan oleh manusia, terciptalah suasana-suasana dan kondisi interaksi yang kemudian memberikan makna tersendiri (Meyrowitz 1990). Munculnya permaknaan ini sangat tergantung pada latar belakang sosial masyarakat itu sendiri. Terbentuklah kemudian masyarakat yang mampu beradaptasi dengan berbagai suasana dan corak kehidupan.

Masyarakat yang tinggal dalam komunitas heterogen perkotaan, menciptakan panggung-panggung sendiri yang membuatnya bisa tampil sebagai komunitas yang bisa bertahan hidup dengan keheterogennya. Begitu juga dengan masyarakat yang homogenya pedesaan, menciptakan panggungpanggung sendiri melalui interaksinya, yang terkadang justru membentuk proteksi sendiri dengan komunitas lainnya. Apa yang dilakukan masyarakat melalui konsep permainan peran adalah realitas yang terjadi secara alamiah dan berkembang sesuai perubahan yang berlangsung dalam diri mereka (Brissett \& Edgley 2005). Permainan peran ini akan berubah- ubah sesuai kondisi dan waktu berlangsungnya. Banyak pula faktor yang berpengaruh dalam permainan peran ini, terutama aspek sosial psikologis yang melingkupinya.

Erving Goffman mengistilahkan tindakan tersebut dalam istilah Impression Management (Goffman 1959). Goffman juga melihat bahwa ada perbedaan acting yang besar saat actor berada diatas panggung (front stage) dan dibelakang panggung (back stage) drama kehidupan. Kondisi acting di front stage adalah adanya penonton yang melihat kita dan kita sedang berada dalam kegiatan pertunjukan. Saat itu kita berusaha untuk memainkan peran kita sebaik- baiknya agar penonton memahami tujuan dari perilaku kita. Pada penelitian ini, perilaku pada frontstage ditunjukan informan pengguna NAPZA dengan tetap membatasi serta mengontrol diri untuk tidak kelewatan dalam bergaul dengan teman pengguna lainnya. Temuan data pada penelitian ini menunjukkan perilaku atau acting yang dilakukan kepada teman, orang lain, lingkungan keluarga, dll yaitu berperilaku seperti biasanya, mempunyai teman di kelas atau teman kuliah, mengikuti kegiatan social, tetap sopan dengan orang yang lebih tua, tetap menjalin interaksi ramah dengan tetangga lingkungan tempat tinggal, dan lainlain, namun informan tetap membatasi jumlah teman yang dimiliki.

Seperti informan $\mathrm{ABO}$ yang di mana dalam berinteraksi $\mathrm{ABO}$ tidak menunjukkan karakter bahwa dirinya merupakan seorang pemakai NAPZA, tetap berinteraksi dengan tetangga, pemuda sebaya dan memiliki rasa sopan kepada orang yang lebih tua. Bahkan ABO turut aktif dalam kegiatan pemuda di wilayah ia tinggal seperti panitia tujuh belas ataupun pada saat gotong royong kerja bakti komplek. Kemudian informan DIO yang memiliki relasi yang lebih luas dan tidak hanya berteman sesama pengguna maupun teman sekolah tapi dirinya juga memiliki pertemanan di luar jaringan tersebut. Misalnya berteman dengan kelompok motor, berteman dan bergabung dalam kelompok Surabaya peduli. Selanjutnya, informan ESA yang tidak menutup diri bahkan aktif dalam kelompok sosial serta menjadi supporter atau pendukung aktif klub Persebaya Surabaya. Selain itu di sekolahnya, ia juga sering menjadi pemimpin supporter pertandingan olahraga. Berbeda dengan infoman BEG dan CSN yang cenderung membatasi pertemanan namun masih tetap menutupi identitasnya sebagai pengguna di teman-temannya, BEG juga dari bentuk fisiknya sama sekali tidak menjukkan kalau seorang pengguna. CSN juga dari bentuk fisik atau postur tubuhnya tidak menampakkan seorang pengguna NAPZA karena informan CSN melakukan olahraga rutin yaitu gym setiap dua minggu sekali.

Kelima informan pada penelitian ini hampir sama ketika berada di lingkungan keluarga, pertemanan, lingkungan sekolah, komunitas sosial, lingkungan tetangga, dan lingkungan lainnya. Action atau acting yang dilakukan sebagai pengguna NAPZA dengan mengaktualisasikan diri, melebur, atau membaur seolah-olah tidak menjadi atau sebagai seorang pengguna NAPZA. Tindakan yang dilakukan kelima informan pada penelitian ini seperti dalam teori Dramaturgi yaitu Impresion Management pada aktor yang berada pada frontstage. Action atau acting ini dijalankan dengan sebaik mungkin agar dapat diterima dan tidak diketahui publik dengan menciptakan kesan yang baik pada 
oranglain. Berbagai acting yang ditemukan dalam temuan data pada penelitian ini yaitu pada informan ABO dan informan BEG yang ketika berada pada lingkungan sekolah atau pertemanan dengan kelompok yang bukan pengguna, informan menunjukkan sikap seperti remaja normal biasanya mempunyai banyak teman dengan menjadi pribadi yang sesuai karakter yang dimiliki seperti bercanda dengan teman-temannya, bermain bersama, nongkrong bersama, mengerjakan tugas sekolah atau tugas kelompok bersama, dsb. Namun informan ABO dan BEG tetap menutupi fakta bahwa informan seorang pengguna NAPZA, agar dapat diterima di kelompok pertemanan tersebut.

Sedangkan back stage adalah keadaan di mana kita berada di belakang panggung dengan kondisi bahwa tidak ada penonton. Sehingga kita dapat berperilaku bebas tanpa memperdulikan plot perilaku bagaimana yang harus kita bawakan. Erving Goffman mendalami dramaturgi dari segi sosiologis. Ia menggali segala macam perilaku interaksi yang kita lakukan dalam pertunjukan kehidupan kita seharihari yang menampilkan diri kita sendiri dalam cara yang sama dengan cara aktor menampilkan karakter orang lain dalam sebuah pertunjukan drama.

Cara yang sama ini mengacu kepada kesamaan yang berarti ada pertunjukan yang ditampilkan. Goffman mengacu pada pertunjukan sosiologi, pertunjukan yang terjadi di masyarakat untuk memberi kesan yang baik untuk mencapai tujuan, ini adalah penerimaan penonton akan manipulasi. Bila seorang aktor berhasil, maka penonton akan melihat aktor sesuai sudut yang memang ingin diperlihatkan oleh aktor tersebut. Aktor akan semakin mudah untuk membawa penonton untuk mencapai tujuan dari pertunjukan tersebut. Ini dapat dikatakan sebagai bentuk lain dari komunikasi, karena komunikasi sebenarnya adalah alat untuk mencapai tujuan.

Pada back stage yang dilakukan oleh kelima informan dalam penelitian ini adalah dengan menjadi pribadi yang lebih bebas, terlihat karakter asli yang dimiliki, tidak memainkan peran, dan bahkan mempunyai sisi yang sangat berbeda jauh ketika berada pada front stage yaitu menjadi lebih petakilan, banyak tingkah dan bahkan menjadi pribadi yang mudah marah atau tersulut emosi. Efek yang disebabkan karena NAPZA adalah menyebabkan informan ketika tidak sadarkan diri karena telah mengkonsumsi NAPZA menjadi emosional, mudah marah bahkan membuat onar. Seperti yang telah dijelaskan bahwa salah satu informan dalam penelitian ini menjadi pribadi yang bebas ketika tidak berada pada front stage yaitu informan ESA yang sering menjadi emosional dan suka membuat onar ketika sedang berada pada back stage atau pada kelompok sesama pengguna NAPZA.

Perilaku remaja pengguna NAPZA di daerah Surabaya berdasarkan teori dramaturgi Erving Gofman adalah memang menggunakan skenario dalam kehidupan sehari-harinya, yang mana seperti dalam lingkup pertemenan sekolah, kelompok belajar, dsb. Remaja pengguna NAPZA menciptakan manajemen kesan untuk menutupi realita sebagai pengguna agar dapat diterima dengan baik dalam lingkungan pertemanan sekolah dan lain sebagainya. Hal tersebut yang dinamakan dengan dramaturgi front stage, dan remaja pengguna NAPZA di Surabaya ketika sudah tidak dalam lingkup pertemanan sekolah, lingkungan kelompok belajar, dll. Cenderung berperilaku yang berbeda dari panggung depan atau front stage, remaja pengguna NAPZA di Surabaya lebih mengeluarkan karakter yang dimilki, lebih merasa bebas, dan bahkan di luar kendali. Hal tersebut dinamakan remaja pengguna pada posisi back stage atau panggung belakang, dimana remaja pengguna NAPZA sudah tidak harus memainkan peran dan memberikan kesan yang baik pada teman-temannya karena sudah tidak dalam panggung teater.

\section{Simpulan}

Kehidupan sosial remaja pengguna NAPZA di kota Surabaya, memiliki perbedaan sikap dan perilaku tersebut karena untuk menutupi identitas bahwa dirinya merupakan seorang pengguna, manjamen kesan pun dilakukan dengan sebaik mungkin seperti tidak akan membocorkan identitas diri pada orang yang baru dikenal. Pada teori Goffman Dramaturgi bahwa ada perbedaan acting yang besar saat actor berada diatas panggung (front stage) dan dibelakang panggung (back stage) drama kehidupan. Perilaku pada front stage ditunjukkan kelima informan adalah menjaga sikap sebaik mungkin agar tidak terlihat sebagai pengguna NAPZA, dengan memperlihatkan, memanipulasi, mengatur perilaku 
sedemikan rupa supaya dapat membaur sebaik mungkin dan dapat terlihat seperti remaja normal kebanyakan juga diharapkan bisa diterima oleh lingkungan atau kelompok sekolah, pertemanan, dan lain-lain. Pada back stage yang dilakukan oleh kelima informan dalam penelitian ini adalah dengan menjadi pribadi yang lebih bebas, terlihat karakter asli yang dimiliki, tidak memainkan peran, dan bahkan mempunyai sisi yang sangat berbeda jauh ketika berada pada front stage yaitu menjadi lebih banyak gurauan, banyak tingkah dan bahkan menjadi pribadi yang mudah marah atau tersulut emosi.

\section{Daftar Pustaka}

Baumeister RF \& Muraven M (1996) Identity as adaptation to social, cultural, and historical context. Journal of adolescence 19 (5):405-416.

Brissett D \& Edgley C (Eds.) (2005) Life as theater: A dramaturgical sourcebook. Transaction Publishers.

Burrow AL \& Hill PL (2011) Purpose as a form of identity capital for positive youth adjustment. Developmental psychology 47 (4):1196.

Crocetti E (2017) Identity formation in adolescence: The dynamic of forming and consolidating identity commitments. Child Development Perspectives 11 (2):145-150.

Goffman E (1959) The Presentation of Self in Everyday Life. New York: Anchor Books.

Halliwell S (1998) Aristotle's poetics. University of Chicago Press.

Kirby JT (2018) Updating Aristotle: A New Norton Critical Edition of the Poetics.

Kroger J (2017) Identity development in adolescence and adulthood. In Oxford research encyclopedia of psychology.

Marcia JE (2010) Life transitions and stress in the context of psychosocial development. In Handbook of stressful transitions across the lifespan (pp. 19-34). Springer, New York, NY.

McBrien J, Dooley K \& Birman D (2017) Cultural and academic adjustment of refugee youth: Introduction to the special issue. International Journal of Intercultural Relations 60:104-108.

Madyaratri SA (2017) Motif perilaku menyimpang remaja dengan kasus penyalahgunaan narkoba di Kota Surabaya. Paradigma: Jurnal Online Mahasiswa S1 Sosiologi UNESA 5 (1).

Meyrowitz J (1990) Redefining the situation: Extending dramaturgy into a theory of social change and media effects. Beyond Goffman: Studies on communication, institution, and social interaction, 65-97.

Moleong LJ (2014) Metode Penelitian Kualitatif. Bandung: PT Remaja Rosdakarya.

Nur'artavia MR (2017) Karakteristik pelajar penyalahguna NAPZA dan jenis NAPZA yang digunakan di Kota Surabaya. The Indonesian Journal of Public Health 12 (1):27-38.

Oleś M (2016) Dimensions of identity and subjective quality of life in adolescents. Social indicators research $126(3): 1401-1419$.

Phinney JS, Lochner BT \& Murphy R (1990) Ethnic identity development and psychological adjustment in adolescence. Sage Publications, Inc.

Pina N, Soedirham O (2015) Dukungan pemerintah dalam mencegah penyalahgunaan narkoba di Kota Surabaya. Jurnal Promkes: The Indonesian Journal of Health Promotion and Health Education 3 (2):171-182.

Prasetyo IJ, Prawiradiredja S \& Jusnita RAE (2019) Patterns of Therapeutic Communication in Rehabilitation Institution for the Narcotics Users in East Java, Indonesia. Journal of Drug and Alcohol Research 8 (2):1-8.

Purwatiningsih S (2001) Penyalahgunaan narkoba di Indonesia. Populasi 12 (1).

Merdeka Online (2017) Jumlah pengguna narkoba di kalangan pelajar Surabaya meningkat. https://www.merdeka.com/peristiwa/tahun-2017-jumlah-pengguna-narkoba-di-kalangan-pelajar -surabaya-meningkat.html. Diakses pada Sabtu, 20 Januari 2018 Pukul 19.25 WIB.

Santoso T \& Silalahi A (2000) Penyalahgunaan narkoba di kalangan remaja: Suatu perspektif. Indonesian Journal of Criminology 1 (1):4232.

Sari DM (2018) Peran kader anti penyalahgunaan narkoba berbasis pelajar oleh Badan Narkotika Nasional Surabaya. Jurnal Promkes: The Indonesian Journal of Health Promotion and Health Education 5 (2):128-140.

Septanto A (2019) Perilaku menyimpang masyarakat penjudi merpati di Surabaya. Jurnal Sosiologi Dialektika 14 (2):126-131. 
Simanungkalit P (2012) Model Pemidanaan yang ideal bagi korban pengguna narkoba di Indonesia. Yustisia Jurnal Hukum 1 (3).

Smith G (2006) Erving Goffman. Routledge.

Spencer MB, Noll E, Stoltzfus J \& Harpalani V (2001). Identity and school adjustment: Revisiting the "acting white" assumption. Educational Psychologist 36 (1):21-30.

Suyatna U (2018) Evaluasi kebijakan narkotika pada 34 provinsi di Indonesia. Sosiohumaniora 20 (2):168-176.

Tseëlon E (1992) Is the presented self sincere? Goffman, impression management and the postmodern self. Theory, Culture \& Society 9 (2):115-128.

Unayah N, Sabarisman M (2016) Fenomena kenakalan remaja dan kriminalitas. Sosio informa 1 (2).

Young K (2018) Personality and problems of adjustment. Routledge. 